\title{
A NEW METHOD FOR THE CALCULATION OF ENERGY AND POWER REQUIREMENTS OF BUCKET WHEEL EXCAVATORS
}

\author{
József ANDRÁS, ${ }^{1}$ József KOVÁCS, ${ }^{2}$ Endre ANDRÁS, ${ }^{3}$ Ildikó KERTÉSZ, ${ }^{4}$ \\ Ovidiu Bogdan TOMUS ${ }^{5}$ \\ University of Petroșani. Department of Mechanical, Industrial and Transports Engineering, Petroșani, \\ Romania \\ 1 iosif.andras@gmail.com \\ ${ }^{2}$ kovacsi@mail.com \\ ${ }^{3}$ andrei.andras@gmail.com \\ ${ }^{4}$ kerteszildiko@ymail.com \\ ${ }^{5}$ tobogdan@gmail.com
}

\begin{abstract}
The bucket wheel excavator (BWE) is a continuous working rock harvesting device which removes the rock by means of buckets armoured with teeth, mounted on the wheel and which transfers rock on a main hauling system (generally a belt conveyor). The wheel rotates in a vertical plane and swings in the horizontal plane and raised / descended in the vertical plane by a boom. In this paper we propose a graphical-numerical method in order to calculate the power and energy requirements of the main harvesting structure (the bucket wheel) of the BWE. This approach - based on virtual models of the main working units of bucket wheel excavators and their working processes - is more convenient than those based on analytical formulas and simplification hypotheses, and leads to improved operation, reduced energy consumption, increased productivity and optimal use of available actuating power.
\end{abstract}

Keywords: bucket-wheel, excavator, power, virtual model.

\section{General considerations}

The method proposed for the determination of the operation power of the rotor has been applied to EsRc-1400 model BWE [1]. This type of excavator is used in the open pit lignite mines in Oltenia.

The geometric characteristics regarding the positioning of the rotor and the rotation mechanism are presented in Figure 1. where the notations used have the following meanings:

$-H_{s}$ - the height of the rotation axis of the boom as against the operating level of the excavator, [m];

$-L_{s p}$ - the distance between the rotation axis of the boom and the rotation axis of the upper platform, [m];

$-L_{p}$ - a- the pivot length of the boom, [m];

$-H_{s p}$ - the distance between the rotation center of the rotor and the lower surface of the boom;
$-B_{r}$ - the distance between the rotation center of the rotor and the symmetry vertical plan of the boom;

$-\delta$ - the angle between the longitudinal axis of the rotor and the pivoting axis of the boom, $\left[^{\circ}\right]$. The arm of the excavator performs in the vertical plane a rising-descending movement around the rotation axis of the boom (Figure 1.).

Horizontally, the rotation movement occurs around the rotation axis of the upper platform with the pivoting speed, $\mathrm{v}_{\mathrm{p}}$ (Figure 2.).

\section{Definition and calculation of cutting parameters}

During the rotation of the bucket wheel, the bucket cuts a sickle-shaped chip defined by points N, F and G (Figure 3). 
The maximum thickness of this chip is $h_{0}$ and it is equal to the length of segments $\mathrm{FG}$ and $\mathrm{O}_{1} \mathrm{O}_{2}$. The geometry defined in Figure 3. is based on bucket wheel radius $R$ relation to segments in the equation:

$$
R=\overline{O_{1} A}=\overline{O_{2} B}
$$

For a rotation angle $\alpha$ of the bucket wheel in regard to the vertical axis we consider the thickness of the chip $h_{i}$, and we determine its size:

$$
h_{i}=\overline{O_{1} A}-\overline{O_{1} B}=R-\overline{O_{1} B}
$$

At the same time it can be seen that:

$$
O_{1} B=B C-O_{1} C
$$

In the rectangular triangle $\Delta \mathrm{BCO}_{2}$ taking into account the relation (2) it can be written that:

$$
\overline{B C}=\overline{O_{2} B} \cdot \cos \lambda=R \cdot \cos \lambda
$$

In the rectangular triangle $\Delta \mathrm{O}_{1} \mathrm{O}_{2} \mathrm{C}$ we can see that:

$$
\overline{O_{1} C}=\overline{O_{1} O_{2}} \cdot \sin \alpha=h_{0} \cdot \sin \alpha
$$

By replacing equations (4) and (5) in equation (3) we obtain:

$$
h_{i}=R-R \cdot \cos \lambda+h_{0} \cdot \sin \alpha
$$

In equation (2) we introduce equation (6) and we can write:

$$
h_{i}=R-R \cdot \cos \lambda+h_{0} \cdot \sin \alpha
$$

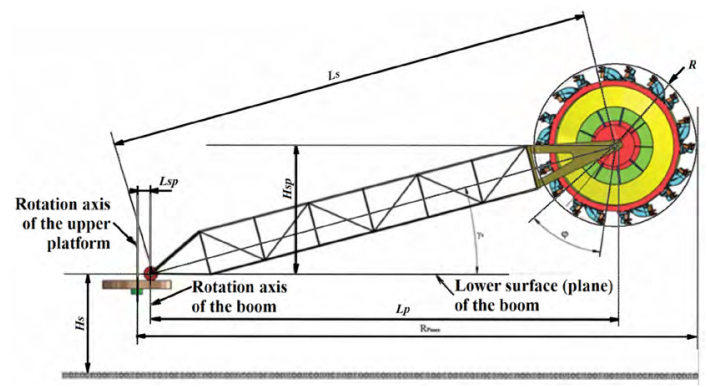

Figure 1. The geometric characteristics of the arm rotor system, side view

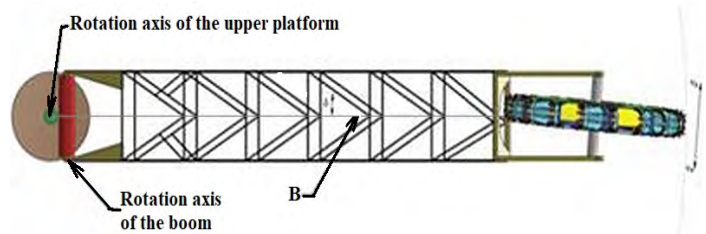

Figure 2. The geometric characteristics of the arm rotor system, top view
Since the angle $\lambda$ is small we can approximate (with an acceptable error) that $\cos (\lambda) \approx 1$, consequently, the equation (16) will become:

$$
h_{i}=h_{0} \cdot \sin \alpha
$$

This equation expresses the variation of the chip thickness according to the rotation angle of the bucket wheel, relative to its maximum thickness.

For the calculation of the chip area, we con-sider the ABED elemental surface. We approximate the area of this surface to that of a rectangle that has a side equal to the instantaneous thickness $t_{i}$ and the other side equal to the length of arc of a circle $\mathrm{AD}$. The length of the arc of a circle AD is calculated with the equations below where the elementary angle $d \alpha$ is expressed in radians:

$$
\overparen{A D}=R \cdot d \alpha
$$

So we can write the area of the ABED elementary surface as:

$$
S_{A B E D}=h_{i} \cdot \widehat{A D}=h_{i} \cdot R \cdot d \alpha=h_{0} \cdot R \cdot \sin \alpha \cdot d \alpha
$$

The total area of the chip surface is obtained by integrating the equation (10) between variation limits of the angle $\alpha$ :

$$
\begin{aligned}
S & =\int_{0}^{\alpha_{0}} h_{0} \cdot R \cdot \sin \alpha \cdot d \alpha=\left.h_{0} \cdot R \cdot(-\cos \alpha)\right|_{0} ^{\alpha_{0}}= \\
& =h_{0} \cdot R \cdot\left(1-\cos \alpha_{0}\right)
\end{aligned}
$$

In order to simulate the chip cutting process and the stresses to which the axis of the bucket wheel is subjected, it is necessary to determine the drive power of the bucket wheel.

We impose a calculation magnitude that we call the effective chip thickness.

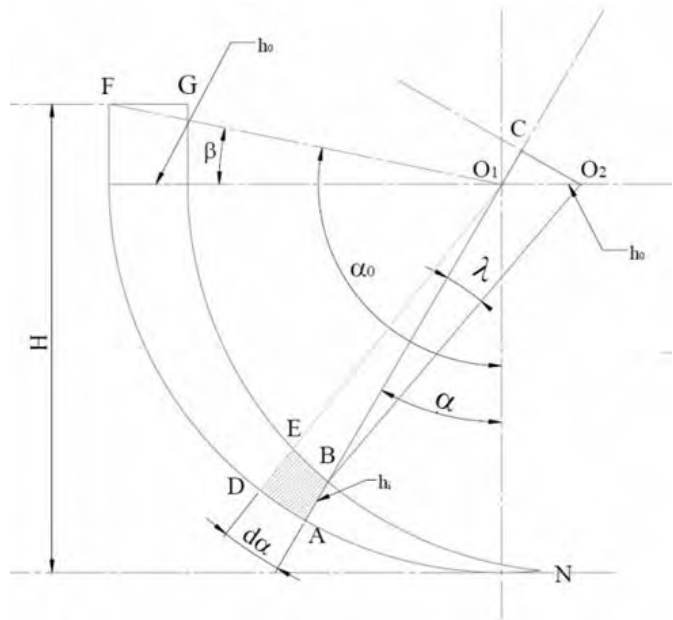

Figure 3. Description of the geometrical dimensions of the cutting of a chip 
It is the measure of the side of a rectangle that has an area equal to the area of the chip section determined by equation (11), and the other side is equal to the length of the arc corresponding to the angle $\alpha_{0}$.

Under these conditions, the area of the chip section in terms of effective thickness will be:

$$
S=h_{e f} \cdot R \cdot \alpha_{0}
$$

By equating the relations (11) and (12) we obtain the expression of the effective thickness of the chip:

$$
\begin{array}{r}
h_{0} \cdot R \cdot\left(1-\cos \alpha_{0}\right)=h_{e f} \cdot R \cdot \alpha_{0} \Rightarrow \\
\Rightarrow h_{e f}=\frac{h_{0} \cdot\left(1-\cos \alpha_{0}\right)}{\alpha_{0}}
\end{array}
$$

The maximum excavation height will be:

$$
\begin{aligned}
H & =R+R \cdot \sin \beta_{0}=R \cdot\left(1+\sin \left(\alpha_{0}-90\right)\right)= \\
& =R \cdot\left(1-\cos \alpha_{0}\right)
\end{aligned}
$$

The time at which this angular advance occurs between two successive cups is:

$$
T=\frac{\varphi \cdot R}{V_{t}}
$$

The chip width equation is:

$$
b=V_{p} \cdot T=\varphi \cdot R \cdot \frac{V_{p}}{V_{t}}
$$

The bulk volume of the bucket must allow the loading of all excavated rock. By denoting by $\mathrm{k}_{\mathrm{a}}$ the coefficient of loosening of excavated rock and $Q$ its volume, we can state that:

$$
b \cdot S \cdot k_{a}=Q
$$

Thus, we can deduce the expression of the maximum width of the excavated chip:

$$
b_{\max }=\frac{Q}{S \cdot k_{a}}=\frac{Q}{k_{a} \cdot h_{0} \cdot R \cdot\left(1-\cos \alpha_{0}\right)}
$$

Figure 4. shows the geometric dimensions that characterize the volume of the excavated chip:

$-B$ - the width of the extracted block;

$-\theta$ - the position angle of the bucket wheel relative to the width of the excavated block.

\section{Theoretical calculation of forces and energy characteristics}

During the excavation process, the energy consumption at the level of the bucket wheel has two major components. Between the two of the components presented above, the energy neces- sary for cutting the material is predominant, representing $60 \ldots 90 \%$ of the energy necessary for operating the bucket wheel:

-the energy necessary for cutting the material to be excavated;

- the energy necessary for lifting the loose material resulting from cutting with the help of the buckets [5], [6].

Determining the energy and power necessary for operating the bucket wheel under certain functioning circumstances is essential for:

- the selection of a BWE from various models;

- the design of new excavators;

-the design of the new cutting - loading systems for existing BWE.

The calculus of the power necessary for cut-ting with rotor excavators can aim at:

- determining the dependence of the power on the parameters of the operating regime for a given excavator;

- optimizing the energetic regime by accomplishing a cutting capacity at minimum energy consumption;

- determining the dependence of the power absorbed by the cutting - loading system on the cutting capacity, respectively the pivoting speed in the working front.

For the BWEs the force characteristics refer to:

-the forces which act on the bucket represented by:

- the cutting force $F_{x}$ which operates according to a direction tangent to the trajectory of the bucket;

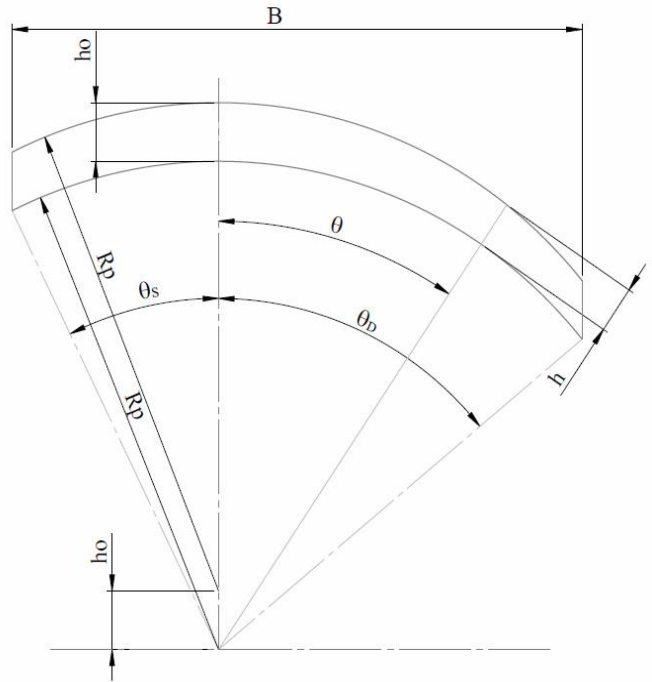

Figure 4. Geometric dimensions that characterize the volume of the excavated chip 
-the penetration force $F_{y}$ which operates according to a normal direction to the trajectory of the bucket;

- the lateral force $F_{z}$ which operates according to a bi-normal direction to the trajectory of the bucket.

- the forces which act on the rotor are represented by:

- the resultant cutting force $F_{x R}$;

- the resultant penetration force $F_{y R}$;

- the resultant lateral force $F_{z R}$.

- the energetic characteristics refer to:

- the power necessary for excavation $P_{e x}$;

-the power necessary for lifting the material $P_{r}$;

-the power necessary to pivot the up-per platform of the excavator, the boom and the rotor $P_{p}$.

The force and energy parameters depend on time and the characteristics of the dislocated chip. In practice, average values are employed so that we have:

According to the above information, the power necessary to drive the rotor will have the expression:

$$
P=\frac{P_{e x}+P_{r}}{\eta_{t}}
$$

where $\eta_{t}$ represents the efficiency of the engine bucket wheel transmission [1], [2].

Thus, the following results:

$$
P=\frac{1}{\Delta t \cdot \eta_{t}} Q_{T}\left[\frac{k_{u z} \cdot K_{e}}{k_{a}}+\frac{1}{\eta_{r}}\left(D-\frac{H}{2}-\frac{2}{3} h_{c}\right) \rho_{a} \cdot g\right] \text { (20) }
$$

where:

$Q_{t}$-the theoretical excavation capacity $\left(3280 \mathrm{~m}^{3} / \mathrm{h}\right)$;

$D$ - the cutting diameter of the rotor $(11,5 \mathrm{~m})$;

$H$ - the height of the bench $(7,5 \mathrm{~m})$;

$k_{u z}$ - the wear degree of the teeth $(1,2)$;

$K_{e}$ - the specific cutting resistance $\left(60 \mathrm{~N} / \mathrm{cm}^{2}\right)$;

$k_{a}$ - loosening coefficient $(1,35)$;

$\eta_{t}$-transmission efficiency $(0,85)$;

$h_{c}$ - the active height of the bucket $(0,84 \mathrm{~m})$;

$\rho_{a}$ - - loose rock density $\left(1,3-2 \mathrm{t} / \mathrm{m}^{3}\right)$.

After applying the relation (20), results a value of the operation power of the excavator rotor of $P=314 \mathrm{~kW}$.

\section{Proposal of a grafo-numeric method of determination of the operation po- wer of the excavator bucket wheel}

Based on these values from Table 1., we have created in SolidWorks a part with a volume defined by trace of the rotor section sliding across the excavation line (Figure 5.). The width of the excavation line is the width $B$ of the extracted block as shown in Figure 4.

We considered an assembly constructed of two identical parts (with geometric links between them) as defined in the previous paragraph. In Figure 6. we present this assembly with the imposed distance of $0.6 \mathrm{~m}$ between the two parts, corresponding to the maximum thickness of the chip (advance step) as defined in Table 1.

The volume of material in an excavated slice is obtained in SolidWorks using the "cavitation" operation applied to the two volume parts defined, as shown in Figure 7. [4]

Using the numerical computing features of SolidWorks, using the cavitation operation for specific volumes, we determined the volume of the excavated slices for two cutting heights: 3.5 or $7.5 \mathrm{~m}$ respectively. The determined volumes are shown in Table 2.

Past research data [1], [2], [3], [4], [7], [8] obtained earlier has highlighted that the specific energy consumption for cutting gray clays is within the range of 0.15 to $0.27 \mathrm{kWh} / \mathrm{m}^{3}$. The energy required for excavation is determined with the equation:

$$
W_{f}=V \cdot w_{s p}
$$

where:

$W_{f}$ - is the total energy required to excavate one slice (kWh);

$V$ - is the volume of one slice $\left(\mathrm{m}^{3}\right)$;

$w_{s p}$ - is the specific energy consumption for cutting based on past research data ( 0.15 to $0.27 \mathrm{kWh} / \mathrm{m}^{3}$ ).

Table 1.

\begin{tabular}{|c|l|c|c|c|}
\hline No. & Characteristic & Symbol & M.U. & Value \\
\hline \multirow{2}{*}{1} & Left / right pivoting & $\theta_{S}$ & \multirow{2}{*}{ Deg. } & 42.80 \\
\cline { 3 - 3 } & angles & $\theta_{D}$ & & 90.00 \\
\hline 2 & Pivoting radius & $R_{p}$ & $\mathrm{~m}$ & 41.68 \\
\hline 3 & $\begin{array}{l}\text { Cutting diameter of } \\
\text { the bucket wheel }\end{array}$ & $D$ & $\mathrm{~m}$ & 11.5 \\
\hline \multirow{2}{*}{4} & $\begin{array}{l}\text { Maximum thickness } \\
\text { of the chip (advance } \\
\text { step) }\end{array}$ & $h_{0}$ & $\mathrm{~m}$ & 0.6 \\
\hline
\end{tabular}


We calculated the power for the minimum, maximum and average values of the specific energy consumption during excavation. Table 2. shows the results obtained.

The excavation time corresponding to the $3.5 \mathrm{~m}$ cutting height was experimentally measured in the open pit mine, its value being 438 seconds (Table 2). For the calculation of the power corresponding to the $7.5 \mathrm{~m}$ cutting height, we considered the same value of the excavation time (438 seconds). It is noted that for a specific energy of cutting of $0.27 \mathrm{kWh} / \mathrm{m}^{3}$, the required power is greater than the nominal power of the drive motor of the bucket-wheel.

For these situations, in practice it is advisable to reduce the pivoting speed of the excavator boom, which will increase the excavation time.

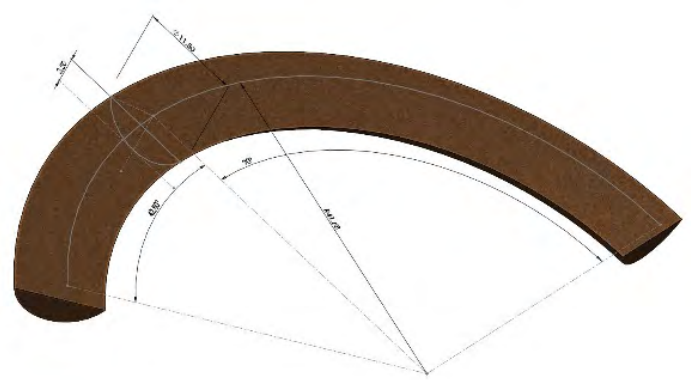

Figure 5. The volume generated by the bucket wheel resulted after a complete swelling movement

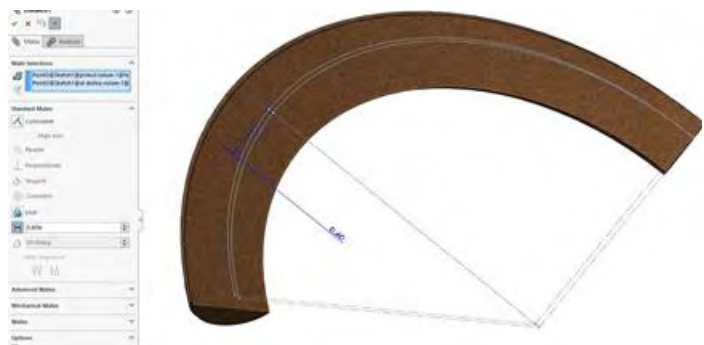

Figure 6. The two decaled volumes defining the chip

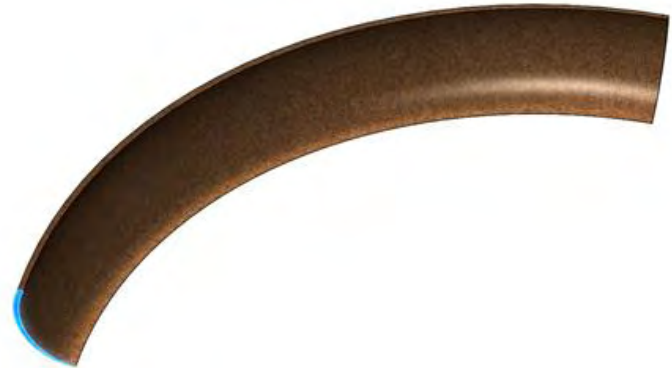

Figure 7. The final shape of the excavated chip
Considering the nominal power of the drive motor of the bucket-wheel as $P_{n}$, then the power required for excavation $P_{\text {ExMax }}$ must be less than it:

$$
P_{\text {ExMax }}<P_{n}
$$

Based on equation (22), we determine the maximum pivoting speed so that the power required for excavation does not exceed the nominal power of the bucket-wheel drive motor for certain defined cutting parameters. Thus, for the limit it can be written:

$$
P_{E x \text { Max }}=\frac{W_{f}}{t_{e x}}=\frac{W_{f} \cdot v_{p \max }}{L} \Rightarrow v_{p \max }<\frac{P_{n} \cdot L}{W_{f}}
$$

where:

$t_{e x} \quad$ - is the excavation time;

$v_{\text {pmax }}-$ is the maximum pivoting speed;

$L \quad$ - is the length of the slice arc;

$P_{n} \quad$ - is the nominal power of the bucket-wheel drive motor $(630 \mathrm{~kW})$.

For the cutting parameters shown in Table 1, the length of the slice arc is $L=96.61 \mathrm{~m}$.

Based on equation (23), the maximum pivoting speed must not exceed $0.224 \mathrm{~m} / \mathrm{s}$

\section{Conclusions}

The paper proposes a way of determining the operation power of the bucket wheel of a BWE using a grafo-numeric method.

The method is based on the modeling of the cutting parameters for the BWE in order to reduce the specific energy consumption during excavation, increasing the excavation capacity while maintaining the minimum installed power of the bucket-wheel drive .

We have developed a chip model resulting from the excavation process with the Solid-Works, obtaining the volume of excavated rock.

Based on past results on specific energy consumption during the excavation process, we de-

\begin{tabular}{|c|c|c|c|c|c|c|}
\hline Nr. & $\begin{array}{l}\text { Cutting } \\
\text { height } \\
\text { (m) }\end{array}$ & $\begin{array}{c}\text { Exca- } \\
\text { vated } \\
\text { volume } \\
\left(\mathbf{m}^{3}\right)\end{array}$ & $\begin{array}{c}\text { Exca- } \\
\text { vation } \\
\text { time } \\
\text { (s) }\end{array}$ & $\begin{array}{c}\text { Specific } \\
\text { energy } \\
(\mathbf{k W h} / \\
\left.\mathbf{m}^{3}\right)\end{array}$ & $\begin{array}{c}\text { Energy } \\
\text { con- } \\
\text { sumed } \\
(\mathrm{kJ})\end{array}$ & $\begin{array}{c}\text { Exca- } \\
\text { vation } \\
\text { power } \\
(\mathrm{kW})\end{array}$ \\
\hline 1 & \multirow{3}{*}{3,5} & \multirow{3}{*}{160} & \multirow{3}{*}{438} & 0.15 & 86400 & 197 \\
\hline 2 & & & & 0.21 & 129960 & 276 \\
\hline 3 & & & & 0.27 & 155520 & 355 \\
\hline 1 & \multirow{3}{*}{7,5} & \multirow{3}{*}{297} & \multirow{3}{*}{438} & 0.15 & 160380 & 366 \\
\hline 2 & & & & 0.21 & 224500 & 512 \\
\hline 3 & & & & & 288600 & 659 \\
\hline
\end{tabular}

Table 2. 
termined the power required for excavation for different cutting parameters.

For the two scenarios considered (3.5 and $7.5 \mathrm{~m}$ excavation heights), the calculated power with the presented method varies between 197 and $355 \mathrm{~kW}$ for the excavation height of $3.5 \mathrm{~m}$ and 366 to $659 \mathrm{~kW}$ for the excavation height of $7.5 \mathrm{~m}$.

For a $3.5 \mathrm{~m}$ excavation height, the average power actually measured was $297 \mathrm{~kW}$, the difference from the value obtained using the proposed method having a deviation within permitted limits.

Because the presented method is based on numerical computational models, it has a general character, and can be applied to any type of BWE, for various rock characteristics and different cutting parameters.

\section{References}

[1] Kovács I., András I., Nan M. S., Popescu F. D.: Theoretical and experimental research regarding the determination of non-homogenons materials mechanical cutting characteristics. $8^{\text {th }}$ WSEAS International Conference on simulation, modelling and optimization (SMO'08) Santander, Cantabria, Spain, September 23-25, 2008.

[2] Kertész (Brînaş) Ildikó: Simularea şi modelarea parametrilor de funcţionare a rotorului excavatoarelor în timpul procesului de excavare. Raport de cercetare nr.2, Petroşani, 2018.

[3] Kovács I., Nan M. S., András I., Jula D.: Study of the working regime of the bucket wheel excavators in the conditions of Romanian open pit lignite mines. $8^{\text {th }}$ WSEAS International Conference on simulation, modelling and optimization (SMO'08), Santander, Cantabria, Spain, September 23-25, 2008.

[4] Kressner M., ş.a.: Cutting Resistance an Cutting Tool Design on Bucket Wheel Excavators. Proceedings of ISCSM 2006, 8TH International Symposium, Continuous Surface Mining, Aachen, September $24^{\text {th }}-27^{\text {th }} 2006$.

[5] Raaz, V.: Optimierung der maschinen- mid Verfahrenrechnischen Parameter von Schaufelradbaggem für einen abbau von harteren Materialen im Tagebau. Braunkohle in Europa: Innovationen für die Zukunft; 1. Internationale Konferenz, 29. Marz bis 1. April 2000. in Freiberg, Tagungsband.

[6] Sümegi I.: Külfejtési marótárcsás kotrógépek jövesztő szerkezetének elméleti vizsgálata és fejlesztése. Doktori értekezés, Miskolci Egyetem, 2002.

[7] András A., Fraur F., Risteiu M.: Overview of the Unwanted Effects of Unmineable Rock Formations on the Mining System of Bucket Wheel Excavator During the Excavation Process. $17^{\text {th }}$ International Multidisciplinary Scientific GeoConference SGEM 2017, Conference Proceedings, 29 June - 5 July, 2017, 17/13. (2017) 637-644. https://doi.org/10.5593/sgem2017/13/S03.081

[8] Tomus O. B., András A., András I.: Study of the Dependence Between the Cutting Direction Relative to Stratification and the Digging Characteristics of Lignite in Oltenia Coal Basin (Romania). $17^{\text {th }}$ International Multidisciplinary Scientific GeoConference SGEM 2017, Conference Proceedings, 29 June - 5 July, 2017, 17/13. (2017) 825-830. https://doi.org/10.5593/sgem2017/13/S03.104 